\title{
Exploration of Major Fungal Pathogens Associated with Water Hyacinth (Eichhornia crassipes (C. Mart) Solms) and Evaluation of their Potential as Mycoherbicides by Proving Pathogenicity
}

\author{
R. Pavithra ${ }^{1 *}$, R. Kannan ${ }^{1}$, V. Ramamoorthy ${ }^{1}$, S. Shenbagavalli ${ }^{2}$ and N. Senthil Kumar ${ }^{3}$ \\ ${ }^{1}$ Department of Plant Pathology, ${ }^{2}$ Department of Soil Science \& Agricultural Chemistry, \\ ${ }^{3}$ Department of Agronomy, Agricultural College and Research Institute, Killikulam, \\ Vallanad-628 252, India \\ *Corresponding author
}

K e y w o r d s
Water hyacinth,
Aquatic weed,
Fungal pathogens,
Fusarium species,
ITS-rDNA and
biocontrol

\section{Ke y w o r d s}

Water hyacinth, Aquatic weed Fungal pathogens, ITS-rDNA and biocontrol

Article Info

Accepted: Available Online: gust 2020

\section{A B S T R A C T}

Eichhornia crassipes (C. Mart) Solms is one of the gregarious and noxious aquatic weed which was invasive to Asian countries. It was spread throughout the country and also infestation of water hyacinth can be seen in many parts of Tamil Nadu along the waterways. The present study was carried out to isolate different fungal pathogens associated with water hyacinth infesting water bodies of Thoothukudi district in Tamil Nadu and to identify the biocontrol potential of the pathogens against water hyacinth based upon their pathogenecity. Twelve fungal pathogens were isolated and subjected to in vitro detached leaf assay and whole plant assay to prove their pathogenicity. The isolated pathogens were produced various symptoms such as leaf spot, blight, chlorosis, necrosis and rotting on the infected leaves. Out of the 12 fungal isolates obtained from the diseased water hyacinth plants, all isolates were pathogenic and the isolates $\mathrm{WH}-5$ and $\mathrm{WH}-11$ found to be more pathogenic to the plants than the other isolates. Based on the morphological and molecular identification, both the isolates belong to the genus Fusarium. The isolates WH-5 and WH-11 caused 60.77 and 66.45 per cent of infection on the plants respectively and having potential to be an effective biocontrol agent for the management of water hyacinth.

\section{Introduction}

Water hyacinth (Eichhornia crassipes (C. Mart) Solms) is one of the invasive and noxious aquatic weed all over the world. According to the International Union for conservation of Nature (IUCN), it was considered as one of the 100 most problematic invasive weed species and top ten worst weed that infested all over the world (Patel, 2012). It belongs to the family Pontederiaceae and it is a perennial, free 
floating aquatic plant and reproduces mainly by means of stolons irrespective of seeds (Henderson, 2001). It was native to South America and first infestation of water hyacinth was reported in Egypt during the period 1879-1892 as an ornamental plant. In 1896, it was introduced in Bengal regions of India as an ornamental plant for its beautiful flowers and leaf shape. It was considered as a terror of Bengal and now it has spread throughout the country. Because of its high reproducing ability and ability to infest wide range of freshwater habitats, it causes serious problems on the environment. It leads to reduction of oxygen level that results in loss of water quality, blocks sunlight, provides breeding ground for the pests and vectors like mosquitoes that causes many vector borne diseases like malaria, filariasis and encephalitis on humans and it also causes detrimental effects on aquatic organisms and affects fisheries, irrigation, navigation, water supply and total ecology of the infested water bodies (Narayanan, 2007).

Water hyacinth management can be done through various methods including mechanical or physical, chemical and biological control. Among the three methods, biological control has been found to be an effective and economic method to control water hyacinth by using their natural enemies (Firehun et al., 2013). Many fungal pathogens have been identified as an effective biocontrol agent worldwide and several species of Alternaria, Cercospora, Acremonium Myrothecium have been studied intensively in experimental conditions (Charudattan, 2001; Shabana et al., 1995; Martinez and Gutierrez, 2001; Praveena and Naseema, 2004). The aim of the present study is to isolate and identify the effective biocontrol agent for the management of water hyacinth and development of the mycoherbicide formulations.

\section{Materials and Methods}

\section{Isolation}

Diseased water hyacinth plants showing symptoms like chlorosis, leaf spot, leaf blight and necrosis were collected and brought to the laboratory. The collected plants were washed under running tap water for $10-15 \mathrm{~min}$. to remove surface debris. The diseased portions were dissected about $1-2 \mathrm{~cm}$ along with healthy tissues using sterile blade. Then the dissected leaf pieces were placed in $10 \%$ sodium hypochlorite about $1 \mathrm{~min}$ for surface sterilization and rinsed thrice with sterile distilled water. After surface sterilization, leaf tissues were placed on a blotting paper to become dry and aseptically transferred into the petriplates containing potato dextrose agar medium and incubated for 5-7 days under room temperature. The inoculated plates were regularly observed for appearance of fungal colonies.

\section{Sub culturing and maintenance of the} isolates

The fungal colonies observed in the isolation plates were aseptically transferred into fresh PDA plates for sub culturing and then the pure culture of fungal colonies were maintained by inoculating them into a sterilized PDA slants and stored at $4{ }^{\circ} \mathrm{C}$.

\section{Pathogenicity test}

The fungal isolates were tested for their ability to produce symptoms in healthy plants. The pathogenicity test was conducted by using two methods viz., in vitro detached leaf assay and whole plant assay.

\section{(a) In vitro detached leaf assay}

Healthy leaves were collected from water hyacinth plants and washed under running 
water. The collected leaves were surface sterilized by using $70 \%$ ethanol and placed in sterile petriplates containing wet germination paper. Then the leaves are painted with tween-80 and wounded artificially with sterile needle. The fungal isolates were inoculated on the leaves at a spore concentration of $1 \times 10^{6} / \mathrm{ml}$ and incubated for 7 days. Inoculated leaves were observed for every $24 \mathrm{~h}$ and disease progression of each isolates was determined using Area under disease progressive curve (AUDPC). Then the AUDPC values were calculated by using the formula

AUDPC $=$

$\sum_{i}^{n-1}\left[\left\{\frac{Y i+Y(i+1)}{2}\right\} \times(t(i+1)-t i]\right.$

Whereas

$Y i=$ disease severity on the $i^{\text {th }}$ observations

$t i=$ day or hours on the $i^{\text {th }}$ observations

$\mathrm{n}=$ number of observations on which symptoms recorded.

\section{(b) Whole plant assay}

Healthy water hyacinth plants were collected and placed in $500 \mathrm{ml}$ glass beaker containing water and acclimatized to the glass house conditions. The plants were wounded artificially by pin prick method and sprayed with spore suspension of fungal isolates at a concentration of $1 \times 10^{6} / \mathrm{ml}$ along with Tween 80 as an adhesive. Then the inoculated plants were covered with polythene bags to maintain humidity. The inoculated plants were observed for the production of disease symptoms regularly up to 30 days.

Disease severity of fungal isolates were observed for every $24 \mathrm{~h}$ and intensity of infection was determined using the score chart developed by Freeman and Charudattan (1984) and designated as: - (no symptom: healthy plant), + (mild symptom: plant showing slight symptoms up to $15 \%$ of leaf area), ++ (moderate symptom: plant showing definite bigger patches of diseased areas from $16 \%$ to $59 \%$ of leaf area) and +++ (severe symptom: enlarged lesions covering 60-100\% of leaf area). Disease was scored using a 0 to 5 scale rating system were $0=$ no symptoms; $1=1-10 \% ; 2=11-25 \% ; 3=26-50 \% ; 4=51-$ $75 \% ; 5=\geq 75 \%$ of leaf area covered by disease symptoms. Then the disease index was calculated by using the formula:

Per cent Disease Index $(\mathrm{PDI})=$

$$
\text { sum of all individual ratings } \mathrm{X} 100
$$

total number of leaves scored Xmaximum score

\section{Morphological and molecular identification of virulent fungal isolates}

For morphological identification, the mycelium color, texture, spore color, shape and size of the fungal isolates were observed under microscope. For molecular identification, the genomic DNA was isolated from 2-3 day old culture of the isolate and subjected to PCR amplification.

The internal transcribed spacer regions of the nuclear rDNA were amplified using ITS1 and ITS4 primers. The amplification was carried out in a total volume of $25 \mu 1$ reaction mixture containing target DNA, double distilled water, PCR master mix, primers ITS1 and ITS4. Initial denaturing step was carried at $94^{\circ} \mathrm{C}$ for five $\min$ followed by 30 cycles of denaturation at $94^{\circ} \mathrm{C}$ for two min. annealing at $57^{\circ} \mathrm{C}$ for one min and elongation at $72^{\circ} \mathrm{C}$ for two min.

The unpurified PCR products were submitted to the Bioserve Biotechnologies (India) Pvt. Ltd, Hyderabad for sequencing and the nucleotide sequence was aligned through nucleotide blast program. 


\section{Results and Discussion}

\section{Isolation}

Diseased water hyacinth plants were collected from the water bodies around Agricultural College and Research Institute, Killikulam. The collected plants showed different types of symptoms like chlorosis, necrosis, leaf spot, leaf blight and rotting of plants. From the diseased plants 12 fungal isolates were obtained. Some of the isolates were identified tentatively and they belong to the genera Curvularia, Fusarium, Helminthosporium and Aspergillus.

\section{Pathogenicity test}

\section{In vitro detached leaf assay}

In the in vitro detached leaf assay, all the 12 isolates produced the disease symptoms in which the isolates WH- 1, 2, 3, 4, 5, 6, 7, 8 and 11 exhibited symptoms about 48 hours of post inoculation (HPI) and the isolates $\mathrm{WH}$ 9, 10 and 12 exhibited symptoms about 72 HPI (Table 1). During the assay, various symptoms were produced which includes chlorosis, leaf spot, leaf blight and drying of the leaves. The isolates WH-6 and WH-11 exhibited higher AUDPC value about 5200 and having more pathogenic potential to plants and the isolate $\mathrm{WH}-12$ exhibited lower AUDPC value about 2720 and having less pathogenic potential to the plants.

\section{Whole plant assay}

Then all the 12 isolates were subjected to whole plant assay for pathogenecity test, in which the isolate $\mathrm{WH}-11$ produced higher PDI value of $66.45 \%$ showing brown spots on the leaves, marginal browning and chlorotic symptoms initially which turned into brown elongated spots with yellow halo. Then the symptoms extends to the petiole and finally results in rotting of the plant and reduce its reproducing ability within 20 days after inoculation. The intensity of infection to the water hyacinth plants ranged from $31.51 \%$ to $66.45 \%$ (Table 2). The isolate WH-11 produced severe symptoms and followed by isolate WH-5. Hence the isolates WH-5 and WH-11 were found to be virulent isolates having more pathogenic potential to the plants (Fig. 1).

\section{Morphological and molecular identification of virulent fungal isolates}

The morphological identification of the virulent isolates $\mathrm{WH}-5$ and $\mathrm{WH}-11$ showed white cottony mycelial growth on the PDA medium with hyaline, septate mycelium, and produces 3-4 septate sickle shaped conidia. The DNA banding of the isolates WH-5 and WH-11 ranged between 500-700bp. (Fig. 2). The sequences of the isolates WH-5 and WH11 thus obtained was showing $93.52 \%$ sequence similarity with Fusarium species. Both the morphological and molecular identification showed that they belong to the genus Fusarium.

Some species of the genus Fusarium were reported as major and common pathogens that infect water hyacinth plants all over the world (Evans and Reeder, 2001). In 1986, Jamil and Rajagopal conducted a survey on the fungal pathogens of water hyacinth from Andhra Pradesh and reported Fusarium oxysporum Schlet that infects water hyacinth. Santhi (1994) reported Fusarium equisiti and $F$. pallidoroseum had an effective biocontrol potential against water hyacinth. Yirefu et al., (2017) reported that $F$. oxysporum, F. equiseti were found to be highly pathogenic to water hyacinth from the rift valley of Ethiopia. In 2012, Ray and Hill conducted a survey from different water bodies of South Africa and reported several isolates of Fusarium species viz., $F$. avenaceum, $F$. oxysporum, $F$. solani and found to be more pathogenic under controlled conditions. 
Table.1 Effect of fungal isolates on water hyacinth during in vitro detached leaf assay

\begin{tabular}{|c|c|c|c|c|c|c|c|}
\hline \multirow{2}{*}{ Isolates } & \multicolumn{6}{|c|}{ Leaf area damaged after different hours post inoculation (HPI) } \\
\cline { 2 - 9 } & $\mathbf{4 8}$ & $\mathbf{7 2}$ & $\mathbf{9 6}$ & $\mathbf{1 2 0}$ & $\mathbf{1 4 4}$ & $\mathbf{1 6 8}$ & AUDPC Value \\
\hline WH-1 & 6.67 & 20 & 26.67 & 26.67 & 46.67 & 53.33 & 3600 \\
\hline WH-2 & 6.67 & 20 & 33.33 & 33.33 & 53.33 & 60 & 4160 \\
\hline WH-3 & 13.33 & 20 & 26.67 & 33.33 & 53.33 & 66.67 & 4160 \\
\hline WH-4 & 6.67 & 13.33 & 26.67 & 33.33 & 40 & 60 & 3520 \\
\hline WH-5 & 6.67 & 20 & 33.33 & 40 & 46.67 & 66.67 & 4240 \\
\hline WH-6 & 20 & 33.33 & 33.33 & 46.67 & 60 & 60 & 5200 \\
\hline WH-7 & 6.67 & 13.33 & 26.67 & 40 & 53.33 & 66.67 & 4080 \\
\hline WH-8 & 6.67 & 13.33 & 26.67 & 40 & 46.67 & 53.33 & 3760 \\
\hline WH-9 & 0 & 6.67 & 20 & 26.67 & 33.33 & 46.67 & 2640 \\
\hline WH-10 & 0 & 13.33 & 20 & 26.67 & 40 & 46.67 & 2960 \\
\hline WH-11 & 13.33 & 20 & 33.33 & 46.67 & 66.67 & 86.67 & 5200 \\
\hline WH-12 & 0 & 13.33 & 20 & 26.67 & 26.67 & 46.67 & 2720 \\
\hline
\end{tabular}

Table.2 Intensity of infection and symptoms produced by the fungal isolates

\begin{tabular}{|l|c|c|c|}
\hline Isolates & $\begin{array}{c}\text { Percent Disease } \\
\text { Index (PDI) }(\%)\end{array}$ & $\begin{array}{c}\text { Intensity } \\
\text { of infection }\end{array}$ & $\begin{array}{c}\text { Symptoms produced } \\
\text { by pathogen }\end{array}$ \\
\hline WH-1 & 33.42 & ++ & Blighting on leaves and petiole \\
\hline WH-2 & 37.07 & ++ & Spots on leaves and petiole \\
\hline WH-3 & 43.28 & ++ & Blighting on leaves and petiole \\
\hline WH-4 & 35.26 & ++ & Leaf spot and chlorosis \\
\hline WH-5 & 60.77 & +++ & Spots on leaves and petiole \\
\hline WH-6 & 40.59 & ++ & Spots on leaves and petiole \\
\hline WH-7 & 41.17 & ++ & Leaf blight \\
\hline WH-8 & 34.85 & ++ & Blighting on leaves and petiole \\
\hline WH-9 & 33.41 & ++ & Leaf spot \\
\hline WH-10 & 31.51 & ++ & Leaf spot \\
\hline WH-11 & 66.45 & +++ & Spots on leaves and petiole \\
\hline WH-12 & 33.20 & ++ & Leaf spot \\
\hline
\end{tabular}

* Intensity of infection: - (no symptom: healthy plant), + (mild symptom: plant showing slight symptoms up to $15 \%$ of leaf area), ++ (moderate symptom: plant showing definite bigger patches of diseased areas from 16\% to 59\% of leaf area) and +++ (severe symptom: enlarged lesions covering $60-100 \%$ of leaf area). 
Fig.1 Pathogenicity of the isolates WH-5 and WH-11
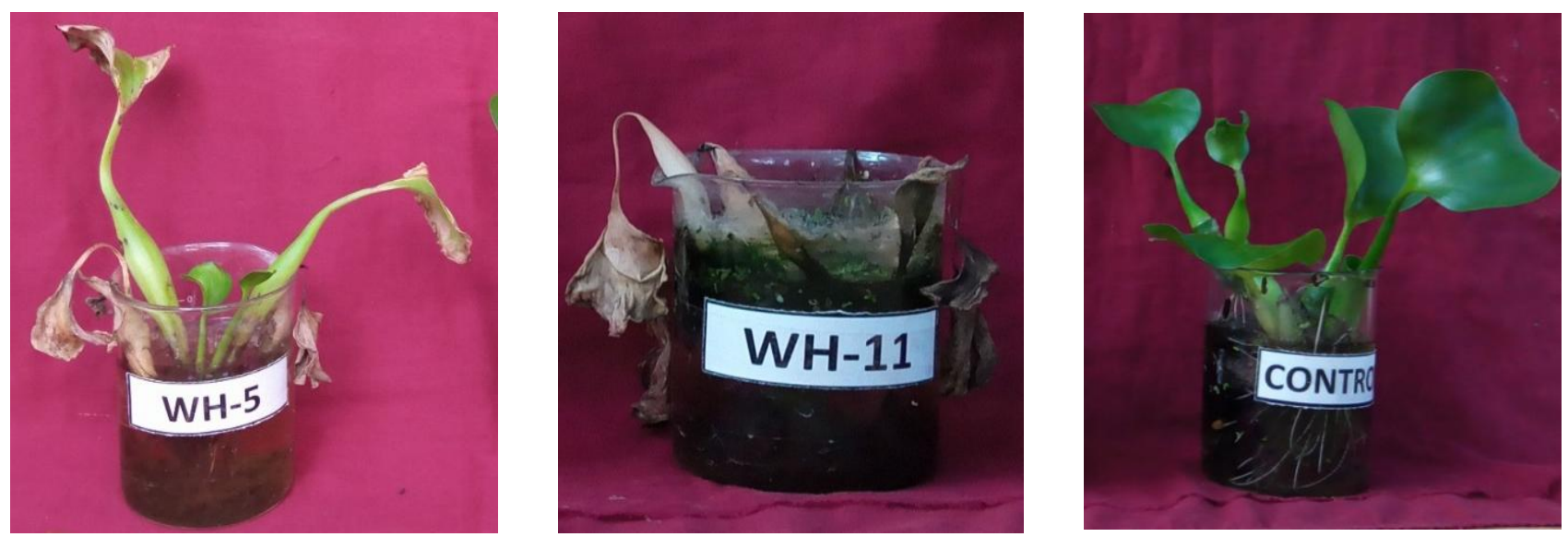

Fig.2 PCR Amplification of the fungal isolates

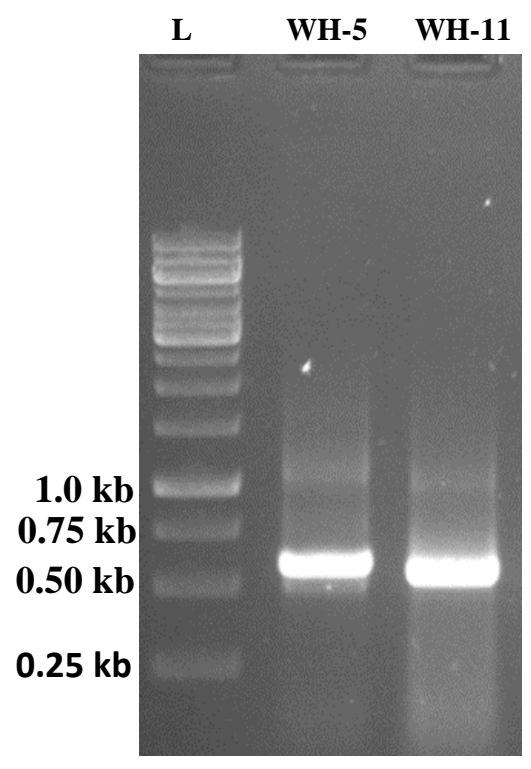

L - Ladder (1kb)

WH-5 \& WH-11 - fungal isolates

The present study concluded that Fusarium species was found to be the most promising biocontrol agent against water hyacinth and also it can be promoted as a mycoherbicide in biocontrol programmes. The isolated Fusarium species was performing well under controlled greenhouse conditions and further studies were carried out to identify their safety against non-target crops, water quality and their effect on soil health.

\section{Acknowledgement}

The authors are grateful to Tamil Nadu State Council for Science and Technology, DOTE Campus, Chennai-600025 for financial support to conduct this research work.

\section{References}

Charudattan, R. (2001). Biological control of weeds by means of plant pathogens: significance for integrated weed 
management in modern agro-ecology. Biol Control. 46:229-260.

Evans, H.C. and Reeder, R.H. (2001). Fungi Associated with Eichhornia crassipes (Water hyacinth) in the upper Amazon basin and prospects for their use in Biological Control, CABI Bioscience, Silwood Park, Ascot, Berks. SL57TA, UK.

Firehun, Y., Struik, P.C., Lantinga, E.A., and Taye, T. (2013). Joint use of insects and fungal pathogens in the management of water hyacinth (Eichhornia crassipes): perspectives for Ethiopia. J Aquat Plant Manage. 51:109-121.

Firehun, Y., Struik, P.C., Lantinga, E.A., and Taye, T. (2017). Occurrence and diversity of fungal pathogens associated with water hyacinth and their potential as biocontrol agents in the Rift Valley of Ethiopia. International Journal of Pest Management. 63:4, 355-363.

Freeman, T.E. and Charudattan, R. (1984). Cercospora rodmanii Conway, a biocontrol agent for water hyacinth. Gainesville, Florida Agriculture Experiment Station Technical Bulletin. 842:18.

Henderson, I. (2001). Alien weeds and invasive plants. Agricultural Research Council, Plant Protection Research Institute. 21pp.

Jamil, K. and Rajagopal, D. (1986). Studies on the mycoflora of water hyacinth. Their individual and combined effect on the phyllosphere. Indian $J$. Microbiol. 26:70-77.
Martinez, J, M. and Gutierrez, E.L. (2001). Host range of Cercospora piaropi and Acremonium zonatum, potential fungal biocontrol agents for water hyacinth in Mexico. Phytoparasitica. 29(2):175177.

Narayanan, S. (2007). Water hyacinth (Eichhornia crassipes) - management of an invasive weed, the Indian scenario. Sarovar Saurabh, vol.3, No.4.

Patel, S. (2012). Threats, management and envisaged utilizations of aquatic weed Eichhornia crassipes; An overview. Reviews in Environmental Science and Biotechnology. 11(3):249-259.

Praveena, R. and Naseema, A. (2004). Fungi occurring on water hyacinth (Eichhornia crassipes (Mart.) Solms) in Kerala. J Trop Agri. 42(1-2):21-23.

Ray, P and Hill, M.P. (2012). Fungi associated with Eichhornia crassipes in South Africa and their pathogenicity under controlled conditions, African Journal of Aquatic Science. 37:3, 323331.

Santhi, K.S. (1994). Screening of fungal pathogens for biocontrol of water hyacinth (Eichhornia crassipes (Mart.) Solms. M.Sc. (Ag.) thesis, Kerala Agricultural University, Thrissur.100p.

Shabana, Y.M., Charudattan, R. and Elwakil, M.A. (1995a). Identification, pathogenicity, and safety of Alternaria eichhorniae from Egypt as a bioherbicide agent for water hyacinth. Biol Control. 5:123-135.

\section{How to cite this article:}

Pavithra, R., R. Kannan, V. Ramamoorthy, S. Shenbagavalli and Senthil Kumar, N. 2020. Exploration of Major Fungal Pathogens Associated with Water Hyacinth (Eichhornia crassipes (C. Mart) Solms) and Evaluation of their Potential as Mycoherbicides by Proving Pathogenicity. Int.J.Curr.Microbiol.App.Sci. 9(08): 1897-1903.

doi: https://doi.org/10.20546/ijcmas.2020.908.217 